\title{
Quando um educador vai para o paraíso
}

\author{
BRUNO PUCCI \\ http://orcid.org/0000-0001-5833-399X \\ Universidade Metodista de Piracicaba \\ Programa de Pós-graduação em Educação \\ Grupo de Pesquisa Teoria Crítica e Educação \\ Piracicaba, SP, Brasil
}

\begin{abstract}
Uma sociedade emancipada não seria nenhum Estado unitário, mas a realização efetiva do universal na reconciliação das diferenças. A política que ainda estiver seriamente interessada em tal sociedade não deveria propagar a igualdade abstrata das pessoas (...). Em vez disso, ela deveria apontar para a má igualdade hoje, (...), pensando, contudo, a situação melhor como aquela na qual é possível ser diferente sem ter medo (ADORNO, Minima moralia, p. 89).
\end{abstract}

Em 1998, quando o Programa de Pós-Graduação em Educação, PPGE/ Unimep, acolheu os professores Maria Cecília Rafael de Góes e Cleiton de Oliveira como seus novos docentes, escrevi um pequeno texto intitulado "Quando novos educadores caem do céu", para apresentá-los aos colegas de trabalho e aos pósgraduandos em exercício ${ }^{1}$. Os dois professores tinham há pouco se aposentado na Unicamp e traziam consigo uma densa experiência acadêmico-científica de que, certamente, todos nós, docente e discentes, e, particularmente o PPGE enquanto um todo, iríamos nos beneficiar como uma dádiva.

Hoje, julho de 2021, 23 anos após a recepção festiva aos colegas de trabalho, volto a ler o texto de 1988, de um lado reconhecendo a contribuição efetiva que os dois colegas docentes proporcionaram ao PPGE/ Unimep no período em que permaneceram entre nós; de outro, lamentando o triste acontecimento de Cleiton de Oliveira nos ter deixado no dia 12 de maio de 2021.

Conheci Cleiton nos anos 1970, quando eu era sacerdote e participava com ele de um encontro religioso em Piracicaba, intitulado TLC $=$ Treinamento de Líderes Cristãos. Posteriormente, por ocasião de meu curso de mestrado na Unimep (1972-1976) tive a oportunidade de ter Cleiton como colega de pósgraduação em educação. Em 1977, $2^{\circ}$ semestre, ingressei na Unimep como professor em tempo integral; Cleiton, docente dessa instituição desde 1973, era também diretor da Faculdade em que lecionei até 1985. Em 1998, de volta à Unimep, reencontramo-nos como professores e colegas no Programa de PósGraduação em Educação e trabalhamos juntos até sua saída da instituição em 2012.

A profissão de ensinar foi a grande paixão de sua vida. Formado docente

1 PUCCI, Bruno. Quando novos educadores caem do céu. In Comunicações, Unimep, Piracicaba, SP, v. 05 , n. 01,1998 , p. $174-177$.

Rev. Bras. Polít. Adm. Educ. - v. 37, n. 2, p. 1125 - 1134, mai./ago. 2021 •1125 
em escola normal de Santa Bárbara d'Oeste, Cleiton lecionou durante 13 anos em escolas de ensino fundamental (1964-1976). Como professor no ensino primário, concursado, trabalhou em diferentes cidades do Estado de São Paulo; a primeira dela foi a pequena Oriente ${ }^{2}$, cidadezinha próxima de Marília, onde eu nasci; nela, bem como depois em Socorro, lecionava na zona rural. Trabalhou como professor do ensino primário também em Pedreira, Americana e Santa Bárbara.

Depois de cursar Pedagogia, na primeira turma desse curso nas, então, Faculdades Integradas do Instituto Educacional Piracicabano (1969-1972), ${ }^{3}$ iniciou suas atividades como docente universitário, em cursos de graduação, nessa mesma instituição, em 1973 e nela permaneceu, como docente até 1982. A partir de 1983, como docente da Universidade Estadual de Campinas, Unicamp, concluiu o mestrado em Educação (Unimep, 1985) e o doutorado em Educação (Unicamp, 1992), iniciando também suas atividades como docente dos programas de PósGraduação. Na Unicamp permaneceu como docente até 1995; nos anos 19961997 foi docente na Universidade de Sorocaba (Uniso) e no Centro Universitário Salesiano (Unisal - Americana). Retornou à Unimep em 1998 e nela permaneceu como docente do PPGE até 2012. Trabalhou, pois como docente - no ensino básico, nos cursos de graduação e de pós-graduação - por 48 anos.

Perguntado, ao final da referida entrevista (nota 3), após a retrospectiva dos 48 anos de magistério nos diferentes graus da docência, se valeu a pena ser professor, educador, ele assim respondeu:

\begin{abstract}
Quando iniciei a atividade docente, não tinha clareza se nela permaneceria por tanto tempo. A descoberta desse mundo encantador e desafiante, que é o magistério, deu-se aos poucos, e quando me dei conta, descobri que passei a vida na escola, atuando desde o fundamental, médio, ensino superior, até a pósgraduação. Foi um período de grandes mudanças na área da educação, desde as concepções de ensino-aprendizagem, as mudanças curriculares, a organização do ensino, as reformas educacionais e as concepções e experiências de administração educacional. Valeu a pena. Tanto que não parei (2015, p. 206-207).
\end{abstract}

2 Na entrevista que Maria Nazaré da Cruz, Cesar Romero Amaral Vieira e eu realizamos com Cleiton sobre sua vida profissional, ele nos conta que, em Oriente, lecionava e morava na zona rural; nos finais de semana ia à cidade; ali seu barbeiro guardava os jornais da semana para que ele pudesse lê-los aos sábados; este barbeiro fazia questão de contar aos demais clientes que Cleiton era professor. Essa entrevista pode ser lida na Revista Comunicações, da Unimep, em 2015 (jul-dez), Ano 22, n. 2, p. 199-207; e também no e-book PUCCI, Bruno. Ensaios Filosófico-Educacionais: Teoria Crítica e Educação, Vol 1. São Carlos: Pedro \& João Editores, 2021, p. $401-$ 414.

3 As Faculdades Integradas do Instituto Educacional Piracicabano se transformaram na Universidade Metodista de Piracicaba, Unimep, em 1975. 
Em 2000 escrevi uma pequena crônica com o título "Professor profissão professar". Cleiton, que já tinha retornado à Unimep em 1998, estava vivendo seu trigésimo sexto ano como professor. Hoje, relendo o aforismo, sinto que seus dizeres expressam de forma intensa "a descoberta desse mundo encantador e desafiante, que é o magistério" e que levou Cleiton a se dedicar integralmente a ele, de maneira corajosa, contínua, que, quando se deu conta, percebeu que tinha passado a vida na sala de aula. A ele, pois, 21 anos após, dedico este painel de sua profissão docente:

Professor, uma profissão em extinção na era da tecnologia avançada, que substitui desapiedadamente a mão de obra improdutiva. Professor, uma profissão ambígua, paradoxal: sentir-se inútil, ameaçado, e, ao mesmo tempo, sentir-se bem com a vida, com os outros. Ser professor, saber professar, reconhecer publicamente, confessar suas afinidades eletivas com os deuses, com a sociedade dos poetas mortos e vivos. Aquele que está sempre envolvido por livros, ideias, escritos, e, de tanto lê-los, ouvi-los, apalpá-los, acaba se tornando um mensageiro ambulante dos vates, dos filósofos, dos homens da vida. Sua experiência se constrói na experiência de outros, dos sábios, dos que têm o saber e o sabor da vida, dos que enxergam o mundo por um olhar novo, esquisito, despretensioso, que causa espanto, ternura, com-paixão. Ser professor, professar os segredos mais íntimos dos poetas e pensadores, e externá-los, à sua maneira, a seus alunos, às pessoas com quem convive, inundando-as de esperanças, mas sobretudo de dúvidas. (...). Ser professor, estar carregado de um campo de forças intenso, potente, e expressar essa tensão nas palavras, nos escritos, no olhar, nos acontecimentos da vida, fazendo com que sua chama incendeie corpos e almas sedentos de ser e de saber. Ser professor, ser sensível às pessoas, ouvi-las, deixá-las se desnudar, sem pejo, não ter nada a lhes oferecer, a não ser a atenção, o silêncio, e, ao mesmo tempo, ser-lhes exigente, ser-lhes brutalmente sincero, fazê-las ousar, ir além de si mesmas, transcender as situações impossíveis. Ouvir os outros e transmitirlhes desejos, mesmo quando seu coração está sendo consumido pelas amarguras cotidianas, e seus dias exauridos pelas dores do existir. Porque ele nada tem, muito pode oferecer, mas nada de importante, de seguro, de tranquilo, de útil. Ser professor é ser anacrônico de seu tempo, que valoriza exclusivamente o que gera troca, haveres, posses. Mas é também ser extemporâneo de seus dias pela crença teimosa no retorno da luz e da canção. Aquele que é vilmente pago para ensinar, que ensina generalidades; que castiga, disciplina e tem o poder da nota e da promoção; que anota, relata e marca a vida dos que em suas mãos estão. Aquele que com-vive, que aparenta força e decisão, que espera muito ser ainda alguém na vida. Ser professor, ser mestre: aquele que ensina, aquele que mais aprende que ensina, que presta atenção no desabrochar dos alunos, e cresce com eles e se sente realizado quando um aluno ouve seus problemas e lhe dá a mão para que a caminhada continue. Ser professor, adotar, abraçar, seguir uma causa, mesmo que sua realização impertinente produza danos pessoais e crises consistentes. Ser professor não é trazer de fora para dentro as qualidades de ensinar, é antes desenvolver de dentro para fora o dom de professar. Professor, profissão professar. ${ }^{4}$ 
Mas Cleiton de Oliveira não foi apenas professor; como docente do ensino superior e, especificamente, de Programas de Pós-Graduação em Educação - e ele o foi de quatro Programas - era como que obrigado a ser pesquisador, seja para avançar teoricamente no conhecimento e crítica das temáticas de sua docência e de intervenção social; seja para acompanhar seus orientandos - iniciantes à pesquisa, mestrandos e doutorandos - na produção do conhecimento científico; seja também pelo compromisso social de buscar a construção de novos saberes e de difundi-los aos diferentes setores da sociedade, particularmente às camadas que não tiveram acesso à vida universitária. E Cleiton cumpriu essa função com empenho e resultados expressivos.

No período de seu retorno à Unimep (1998) como docente do Programa de Pós-Graduação em Educação, desenvolveu, como líder, junto com orientandos e membros de seu Núcleo de Estudos e Investigação, os seguintes projetos de pesquisa: "Descentralização, Municipalização e Políticas Educativas" (1998 -2001); "Os Conselhos Municipais de Educação da Região Metropolitana de Campinas: organização e funcionamento" (2002 - 2004); "A Câmara Temática de Educação na Região Metropolitana de Campinas" (2005 - 2007); "Financiamento do Ensino Básico Brasileiro" (2007 - 2010); "Processos de gestão, autonomia escolar e órgãos colegiados: conflitos, contradições e negociações” (2009 - 2012). E mesmo depois de sair da Unimep, como docente aposentado da Unicamp, desenvolveu seu último projeto de pesquisa: "Políticas Educacionais na Região Metropolitana de Campinas: regime de colaboração" (2012 - 2016). Podemos perceber pelas temáticas abordadas em seus projetos de pesquisa que a área da Educação e, particularmente, a subárea da Administração Escolar foram as guias orientadoras de suas investigações científicas.

Cleiton foi, sem dúvida, um expert nessa subárea do saber e em suas ramificações e especificidades; e trouxe contribuições e orientações para um número significativo de graduandos, pós-graduandos e doutores, que tiveram o privilégio de serem seus orientandos, seus parceiros na busca do conhecimento, seus alunos de graduação e de pós-graduação. $\mathrm{O}$ mestre orientou graduandos na elaboração de monografias de conclusão de cursos, de projetos de iniciação científica; orientou dissertações de mestrandos e teses de doutorandos. Vamos destacar os dois últimos modelos de orientação - de mestrandos e de doutorandos -, que exigiram mais empenho e dedicação de sua parte e, ao mesmo tempo, mais reconhecimento e gratificação humana.

Orientar um mestrando significa conviver com ele pelo menos dois anos e meio; indicar-lhe as disciplinas a serem cursadas; participar das atividades do Núcleo de Pesquisa, ao qual orientador e orientando pertencem; acompanhar o cumprimento das Atividades Supervisionadas e referendá-las; guiá-lo na redação 
de sua dissertação, preparando-o para o Exame de Qualificação; encorajá-lo nos momentos de desânimo e de tensões; ir com ele até o fim: ou seja, até a defesa da dissertação e, depois, acompanhá-lo ainda nas possíveis alterações sugeridas pela banca de defesa. E Cleiton orientou 37 dissertações de mestrado, 28 das quais no PPGE/Unimep.

O processo de orientação de um doutorando é mais longo, normalmente é de 48 meses, com a possibilidade de uma prorrogação de até 06 meses. O orientador, além de conviver com seu orientando por muito mais tempo, deve ainda intensificar seu trabalho de acompanhamento e de orientação porque se exige de um doutorando a defesa de uma tese que goze de originalidade e dos predicados de um trabalho científico de peso e de fôlego. Muitos doutorandos já viveram a experiência de participar, como graduandos, de um projeto de Iniciação Científica e, como mestrandos, de produzir uma monografia científica mais elaborada. No doutorado, é-lhe exigido muito mais, no desenvolvimento das disciplinas do curso, no tempo disponível para elaborar a tese, na obrigatoriedade de cumprir outras exigências, tais como apresentar uma Comunicação Científica em pelo menos 01 evento acadêmico; encaminhar 01 artigo científico para ser publicado em Revista reconhecida pela CAPES. Portanto, o trabalho de um orientador de doutorado é longo, intenso, permeado de diálogos, de correções e de acompanhamento criterioso e muitas vezes de tensões. Mas também é muito gratificante quando o orientador participa da defesa da tese de seu orientado na companhia de outros quatro doutores arguidores; sobretudo quando o orientando desenvolveu um bom trabalho e consegue apresentá-lo e defendê-lo com clareza e competência. E o Dr. Cleiton de Oliveira orientou 20 teses de doutorado, das quais 18 no PPGE/Unimep. Que experiência maravilhosa desenvolveu Cleiton ao acompanhar, como docente de Programas de Pós-Graduação, as atividades acadêmico-científicas de 37 mestrandos e de 20 doutorandos! Quantos diálogos construtivos, quantos problemas enfrentados e resolvidos, quantos conhecimentos elaborados e adquiridos, quantas amizades criadas, relembradas e que perduram, enquanto perdurar a vida e até depois ...!

Mas Cleiton não foi apenas docente do ensino superior, pesquisador científico e orientador de mestrandos e doutorandos. Suas atividades universitárias vão muito além de tudo isso. Ele tinha, como vimos, outras missões a cumprir: prestar contas à sociedade pelo privilégio de ter cursado o ensino superior e de ser docente de uma universidade, particularmente de um Programa de PósGraduação. E, para tal, devia socializar os conhecimentos adquiridos por suas investigações científicas. Cleiton realizou esse imperativo ético com lealdade e 
entusiasmo. E ao concretizar essa incumbência, teve em vista sempre questões relacionadas à educação, à escola pública, ao ensino municipal. Levanto aqui alguns dados que comprovam a argumentação acima:

- Cleiton escreveu 18 artigos científicos e participou como entrevistador de três docentes do PPGE/Unimep: José Luis Sigrist (2003), Hugo Assmann (2009) e Valdemar Sguissardi (2011); 09 dos 18 artigos foram escritos em parcerias com docentes e/ou orientandos; seus 03 primeiros artigos foram elaborados em parceria com seu orientador de mestrado e de doutorado, Newton César Balzan e com Sônia Giubilei;

- Cleiton participou da organização de três livros científicos e como coautor de outros 3 livros, em parceria com colegas docentes universitários. Destaco o livro "Orientadores em Foco: o processo da orientação de teses e dissertações em Educação”, elaborado em coautoria com Roseli Schnetzler e com a colaboração de seus orientandos, tendo como material de pesquisa entrevistas realizadas com docentes orientadores do PPGE/Unimep; o livro foi publicado pela Liber Livros, de Brasília, em 2010, com 137 páginas. Tive o prazer de fazer parte desse trabalho coletivo, como orientador entrevistado. Participei com Cleiton e também com Raquel Gandini e José Maria Paiva, da elaboração do livro

"Trinta Anos de Pós-graduação em Educação do PPGE/Unimep: ensaios, dissertações e teses", publicado pela Editora da Unimep, Piracicaba, em 2002;

- Cleiton foi autor de 26 capítulos de livros, 14 escritos por ele, individualmente, e 12 em coautoria com docentes doutores e com pós-graduandos. Destaco o artigo A terceirização do ensino municipal e o trabalho docente, escrito em parceria com Iara Bonin et alii, publicado pela EDIPUCRS, de Porto Alegre, em 2008. Motivo do destaque: o artigo em pauta analisa, já em 2008, o trágico fenômeno da "terceirização do ensino municipal" e a acentuada pauperização do trabalhador docente; fenômeno este que, nos dias de hoje, em nosso país, está se transformando na maneira usual de os poderes públicos administrarem o ensino municipal; entregando-o à gestão das Organizações Sociais, OSs e das OSCIPs Organização da Sociedade Civil de Interesse Público, com grande prejuízo para os docentes e para a Educação.

E quais as temáticas fundamentais desenvolvidas e analisadas, individualmente e/ou em parcerias, nos mais de 50 textos científicos, em forma de artigos, livros e capítulos dos livros? São problemáticas relacionadas à área da Educação e à subárea da Administração da Educação, entre elas: Plano Nacional de Educação; Legislação do ensino; Financiamento do Ensino; Gestão e política educacional; Descentralização do Ensino; Terceirização do ensino municipal; Conselhos Municipais de Educação. 
Essas temáticas acompanharam Cleiton não apenas em seus escritos científicos, nas disciplinas lecionadas por ele, nos projetos de pesquisas desenvolvidos por seu grupo de estudo; elas se manifestaram de forma contínua e progressiva em outras interlocuções de nosso colega que se foi, mas permanece, saudoso, entre nós, tais como:

- em 36 trabalhos completos e/ou resumidos publicados em Anais de Congressos Científicos;

- em 60 Conferências e/ou Comunicações apresentadas em diferentes atividades acadêmicas nacionais.

Percebemos, através desses dados, que a paixão de Cleiton pela escola, pela sala de aula, pelas questões administrativas relacionadas à educação, particularmente à educação municipal, expressou-se de diferentes formas e momentos, através de atividades específicas: ensino, orientação, produção científica, conferência, divulgação dos conhecimentos adquiridos.

Todos nós que trabalhamos na pesquisa e na produção científica sabemos o quanto de leitura, de reflexão, de esforço de redação se gasta na elaboração de um artigo científico, na preparação de uma palestra ou de uma intervenção num Congresso ou num Simpósio. Como diz Adorno, no aforismo "Lacunas", e Minima Moralia, o conhecimento não cai do céu. "Ao contrário, o conhecimento se dá numa rede onde se entrelaçam prejuízos, intuições, inervações, autocorreções, antecipações e exageros, em poucas palavras, na experiência, que é densa, fundada, mas de modo algum transparente em todos os seus pontos" ${ }^{\prime 5}$. Daí sua extrema dificuldade em ser elaborado.

O debate, a participação em grupos de trabalho no interior e fora da Universidade, a defesa pública de uma causa, a militância partidária, não são as únicas formas de ação política de um cidadão. Cleiton agiu politicamente, sobretudo, pela sua produção científica, pelos seus escritos e conferências. Quantos estudantes e pesquisadores em nosso país não ouviram com atenção seus ensinamentos e não desenvolveram atitudes benfazejas em diálogo com eles?

Ele entendeu, com sabedoria, que a teoria, assim como as exposições reflexivas, são também uma forma de práxis, de intervenção política. Ele aprendeu a penetrar com olhar profundo na essência das coisas. À semelhança de Theodor Adorno poderia exclamar: "Todas as vezes que intervim de maneira direta, em sentido estrito, com visível influência prática, isso ocorreu através da teoria". ${ }^{6}$

5 ADORNO, Theodor. Minima Moralia: reflexões a partir da vida danificada. Trad. Luiz Eduardo Bicca. São Paulo: Editora Ática, 1992, p. 69.

6 ADORNO, Theodor, Notas marginais sobre teoria e práxis. In Palavras e Sinais: modelos críticos 2. Trad. de Maria Helena Ruschel. Petrópolis: Vozes, 1995, p. 229. 
Mas é preciso ressaltar uma outra atividade relacionada à área da Educação e, particularmente, à subárea da Administração da Educação, assumida por Cleiton: sua dedicação e experiência como gestor, no interior da universidade, e também na esfera pública, em atividades relacionadas a seu trabalho em organizações nacionais e na administração escolar em sua cidade natal. Vamos por parte:

Cleiton, na Unimep, foi Chefe do Departamento de Educação de 1975 a 1976, Diretor do Centro de Ciências Humanas de 1977 a 1978; voltou a ser Chefe do Departamento de Educação de 1979 a 1982 e se tornou coordenador do Curso de Pedagogia, de 1981 a 1982. Portanto, ocupou cargos administrativos de chefia de 1975 até 1982, na Unimep. Foi o período em que a Instituição tinha se transformado em Universidade e estava se desenvolvendo quantitativa e qualitativamente, na expansão de cursos novos, na contratação de professores, no aumento do número de alunos provindos de Piracicaba e das cidades da região, sob a Reitoria do Dr. Richard Senn. O Centro de Ciências Humanas, com os cursos de Pedagogia, Letras, Psicologia e Ciências Sociais, nos períodos matutinos e noturnos, na época, tinham suas salas de aulas repletas de alunos. E Cleiton foi um dos principais administradores do referido Centro nesse período inicial de sua história.

$\mathrm{Na}$ Unicamp, nosso mestre coordenou os Cursos de Licenciatura de 1992 a 1995. E são muitos os cursos de Licenciatura dessa universidade estadual, entre eles: Pedagogia, Filosofia, História, Ciências Sociais, Letras, Matemática, Educação Física, Artes - Dança, música, artes visuais -, Ciências Econômicas, Ciências Biológicas, Física e Química.

E, em seu retorno à Unimep, em 1998, coordenou o Programa de PósGraduação em Educação de 2007 a 2009, período difícil, em um momento em que a Unimep começou o seu triste desmonte enquanto instituição universitária de excelência. Cleiton, pois, viveu, na Unimep, momentos intensos e contrastantes; momentos de expansão de cursos, de docentes e de graduandos; e momento de desarticulação da universidade, quando a Unimep foi perdendo gradativamente sua autonomia estatutária e passou a ser administrada, de forma externa, pela rede metodista. Mas em todos esses momentos, Cleiton soube se portar com dignidade e responsabilidade, pela forma discreta e dialógica de conduzir as atividades individuais e coletivas. E a imagem que deixou, particularmente na Unimep, foi a de um gestor que soube ser competente, humilde e solidário com seus colegas docentes e com os graduandos e pós-graduandos que estudaram na Unimep durante seus 10 anos como administrador de Curso de Graduação, do Programa de Pós-Graduação, do Departamento de Educação e do Centro das Ciências Humanas. 
Como mestre e doutor na subárea de Administração da Educação, Cleiton participou de outras atividades políticas e técnicas fora da Universidade, mas em íntima conexão com ela. Foi membro do Conselho Estadual de Educação do Estado de São Paulo por 2 anos, de 1989 a 1991; filiou-se à ANPAE - Associação Nacional de Política e Administração da Educação, desde sua fundação, em 1990 e se tornou diretor dessa entidade no Estado de São Paulo por 4 anos; foi também membro do Conselho Fiscal da ANPAE de 2008 a 2010 e seu Secretário de 2011 a 2014. Filiou-se também à ANPEd - Associação Nacional de Pós-Graduação e de Pesquisa em Educação, e à SBPC - Sociedade Brasileira de Progresso da Ciência. Ou seja, Cleiton não reduziu suas atividades político-científico-educacionais ao interior da Universidade; sentiu necessidade e participou de forma atuante e constante nessas três entidades nacionais durante a maior parte dos anos em que trabalhou no Ensino Superior.

Mas sua atuação político-educacional foi além de sua participação nas organizações acima mencionadas. Entre 1983 e 1988, foi Dirigente Municipal de Educação em Santa Bárbara d'Oeste e também responsável pela fundação do Museu da Imigração, até hoje em funcionamento no município ${ }^{7}$. Enquanto dirigente municipal de Educação foi também membro fundador da Undime União Nacional dos Dirigentes Municipais de Educação (1986) e Presidente do Conselho dessa organização no Estado de São Paulo (1986-1988). Desde 2015, a creche no Jardim São Camilo, de Santa Bárbara d'Oeste, traz o nome de "Professor Cleiton de Oliveira".

No texto de 1988 em referência à acolhida de Cleiton e de Maria Cecília Goes no PPGE/Unimep fiz a seguinte observação, que vale também para ressaltar as atividades acadêmico-científico-educacionais de Cleiton de Oliveira em suas atividades político-educacionais:

Examinar o curriculum vitae de um docente é sempre se defrontar com os dados, com os elementos empíricos de seu trabalho acadêmico, mas é também se defrontar com o mistério, com o desconhecido que constituem o mais profundo do ser de uma pessoa. Um curriculum vitae, por mais completo que seja, é sempre informativo, preciso, objetivo. Nele são elencados os anos de trabalho, os números de publicações, a quantidade de orientandos que completam sua vida ativa. O conjunto das atividades ali expostas nos permitem ponderar a qualificação, a competência, a produtividade. Mas, muitas outras manifestações de vida se aninham ocultamente nas frestas daquelas páginas escritas e abrem para nós outros cantos e encantos (PUCCI, 1998, p. 174).

\footnotetext{
7 O Museu da Imigração foi criado para preservar a memória de Santa Bárbara d'Oeste, dos imigrantes que por ela procuraram, particularmente os norte-americanos, que, após o término da Guerra de Sucessão - no final do século XIX -, se estabeleceram no município e redondezas. Hoje o Museu desenvolve atividades de exposições e de apresentações de obras de arte, de cursos formativos e de outras atividades culturais.
} 
Foi o que tentamos mostrar e desvendar pela exposição de seus anos como docente, pesquisador, orientador, gestor e membro ativo de destacadas organizações político-educacionais brasileiras. Certamente o conjunto da obra aqui exposta e comprovada teve o objetivo de tentar apresentar, mesmo que de forma incompleta e claudicante, a grandeza, a competência e a contribuição sociopolítica da pessoa humana, do cidadão ativo e persistente, que foi Cleiton de Oliveira em seu percurso terreno. Em nenhuma das atividades aqui elencadas na caracterização de sua atuação acadêmica e/ou política foram detectados, de sua parte, desavenças, injustiças, falta de cooperação, egoísmo, busca de interesses puramente pessoais. Trago mais duas observações curriculares para ratificar minha observação. Cleiton de Oliveira foi convidado, aceitou e participou de 82 bancas de defesas de Teses de Doutorado e de 102 bancas de defesa de dissertações de mestrado. Foi pela sua competência, pelo seu espírito dialógico, crítico e contributivo, que, certamente, foi convidado pelos orientadores, com aprovação dos pós-graduandos participantes das referidas 184 bancas. E ainda, movido por seu espírito solidário e contributivo, mesmo depois de se retirar das atividades universitárias, em 2012, continuou como colaborador no Programa de Pós-Graduação em Educação da Unimep e, também, como pesquisador do LAGE - Laboratório de Gestão Educacional da Faculdade de Educação da Unicamp.

A delicadeza entre os seres humanos nada mais é do que a consciência da possibilidade de relações isentas de interesse. (ADORNO, Minima moralia, p. 34)

Eu, de minha parte, só tenho que agradecer às circunstâncias da vida que me levaram a conhecer Cleiton, desde 1970, e por 51 anos gozar de sua amizade e de sua companhia. Esse ser humano não tem par! Pena que Deus o levou cedo demais para praticar o bem em outras paragens!

Piracicaba, julho de 2021.

\section{Bruno Pucci}

Professor Titular aposentado da UFSCar (1996); Professor Titular da Unimep (1977-1985; 1997-2019). Membro do Grupo de Pesquisa Teoria Crítica e Educação; ex-pesquisador sênior do CNPq. Email: puccibru@gmail.com 